\title{
Geodetic constraint on the slip distribution of the 2006 Central Kuril earthquake
}

\author{
Hiroaki Takahashi and Minoru Kasahara \\ Institute of Seismology and Volcanology, Graduate School of Science, Hokkaido University, Sapporo, Hokkaido 060-0810, Japan
}

(Received April 13, 2007; Revised August 8, 2007; Accepted September 6, 2007; Online published October 19, 2007)

\begin{abstract}
We have investigated the slip distribution of the 15 November 2006 Central Kuril earthquake off Simushir Island using continuous GPS data. A dense GPS network on Hokkaido Island, northern Japan, and Sakhalin Island detected coseismic horizontal displacements of $\sim 9 \mathrm{~mm}$ despite large epicentral distances of about $900-$ $1200 \mathrm{~km}$. Eastward displacements at the sites decrease to the south, and this spatial distribution feature constrains the slip on the three subfaults. Our data suggest that little slip has occurred in the southern and northern parts, but that a 6-m slip has occurred in the center of the focal region. This interpretation fits well with the detailed slip distribution inferred from teleseismic waveform inversions. The total seismic moment, $2.8 \times 10^{21} \mathrm{~N} \mathrm{~m}$, is approximately the value indicated using by the Global CMT solution. Our result implies that there remains a seismic gap between this event and the 1952 great Kamchatkan earthquake that is large enough for an $M>8$ earthquake.
\end{abstract}

Key words: 2006 Central Kuril earthquake, GPS, slip distribution, seismic gap.

\section{Introduction}

The 15 November 2006 Central Kuril earthquake (Global Centroid Moment Tensor (CMT) $M_{\mathrm{w}}=8.3$ ) occurred off Simushir Island in the central Kuril Islands, at a location where the Pacific plate is subducting at a rate of $8.4 \mathrm{~cm} / \mathrm{yr}$ (DeMets et al., 1994). Focal mechanism indicates shallow dipping thrust faulting (Fig. 1), suggesting that this event was a typical interplate earthquake on the plate interface.

This focal region corresponds to the last seismic gap along the Kuril subduction zone, which was first pointed out by Fedotov (1965). This gap has endured at least 89 years if we assume that the adjoining $1915(M=8.1)$ and 1918 $(M=8.3)$ events partially filled it. This silent status has led some researchers to suggest possible aseismic behavior of this segment (Song and Simons, 2003). However, the 2006 earthquake represents a seismic faulting in this segment and requires interseismic coupling on the plate interface.

In this article, we analyze continuous GPS data to investigate the slip distribution on the seismic fault and to provide constraints on the seismic rupture of this earthquake.

\section{GPS Data and Analysis}

The Geographical Survey Institute of Japan operates a nationwide GPS network over the Japanese Islands (GEONET) with more than 1000 sites. The RINEX raw data from these are freely available to researchers. We selected 107 GPS sites on the northern and eastern parts of Hokkaido Island from GEONET, and YSSK from International GNSS Service (IGS) (Beutler et al., 1999) for analysis. The epicentral distances of these sites vary from 900 to

Copyright (c) The Society of Geomagnetism and Earth, Planetary and Space Sciences (SGEPSS); The Seismological Society of Japan; The Volcanological Society of Japan; The Geodetic Society of Japan; The Japanese Society for Planetary Sciences; TERRAPUB.
1200 km (Fig. 1).

Data were processed using the Bernese GPS Software (Hugentobler et al., 2001) with IGS precise ephemeris, International Earth Rotation and Reference System Service earth orientation parameters, and International Terrestrial Reference Frame 2000. Site coordinates were estimated daily based on the position of the IGS site TSKB, which is located at an adequate distance from the epicenter (delta $=14^{\circ}$ ) and is strongly constrained.

Figure 2 provides examples of daily site coordinates. Clear coseismic offsets were recognized, especially in the EW component between 14 and 15 November. To extract coseismic signals more precisely, we followed the high-precision method used in the Bernese software. An ADDNEQ module was used to stack normal daily equations for a 4-day period before and after the earthquake event (Hugentobler et al., 2001). Data obtained from November 15 was excluded because they contain both pre- and co-seismic signals. By comparing the site coordinates of these periods, we acquired the final data of the coseismic horizontal displacement at the GPS sites.

Figure 3 indicates the coseismic horizontal displacement field. The maximum coseismic jump is observed at YSSK, which moved $9 \mathrm{~mm}$ to the east. Sites on northern Hokkaido Island also showed eastward displacements of $\sim 6 \mathrm{~mm}$. The amplitude of the eastward displacement decreased gradually to less than $1 \mathrm{~mm}$ on the southern part of Hokkaido Island. These observations clearly indicate regular variations in the displacement vectors from north to south, reflecting the heterogeneous slip distribution on the seismic fault.

\section{Slip Distribution Estimation}

In order to estimate the slip distribution, we divided the aftershock region of the first week into three subfaults 

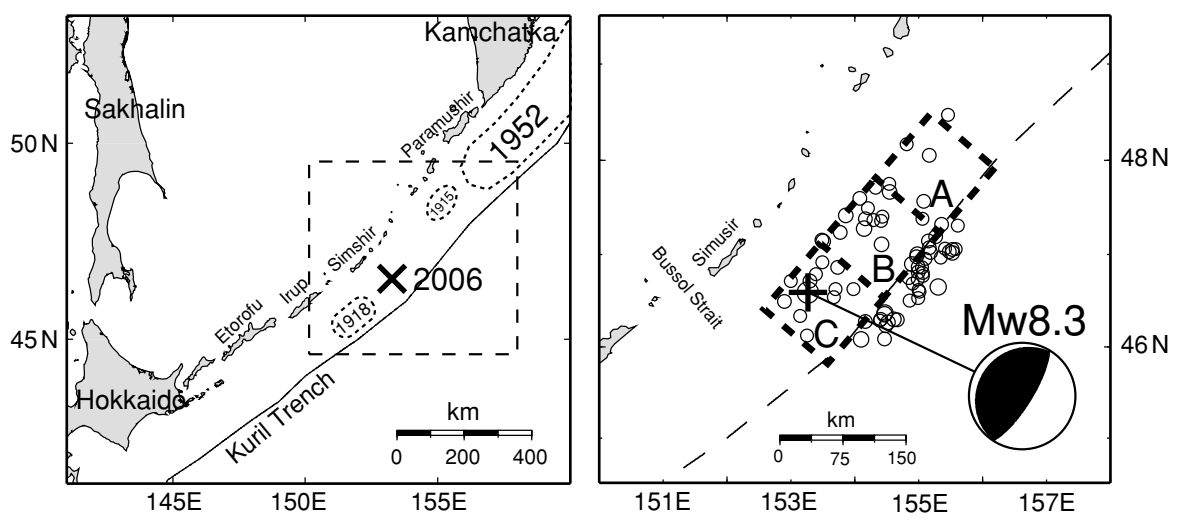

Fig. 1. Map showing the epicentral information of the 2006 Central Kuril earthquake. Focal regions of the neighboring 1915,1918 , and 1952 earthquakes from Fedotov (1965) are also shown (left). Aftershocks and focal solution are from USGS QED information and the Global CMT solution, respectively. The subfaults used in this study are represented by rectangles (right).
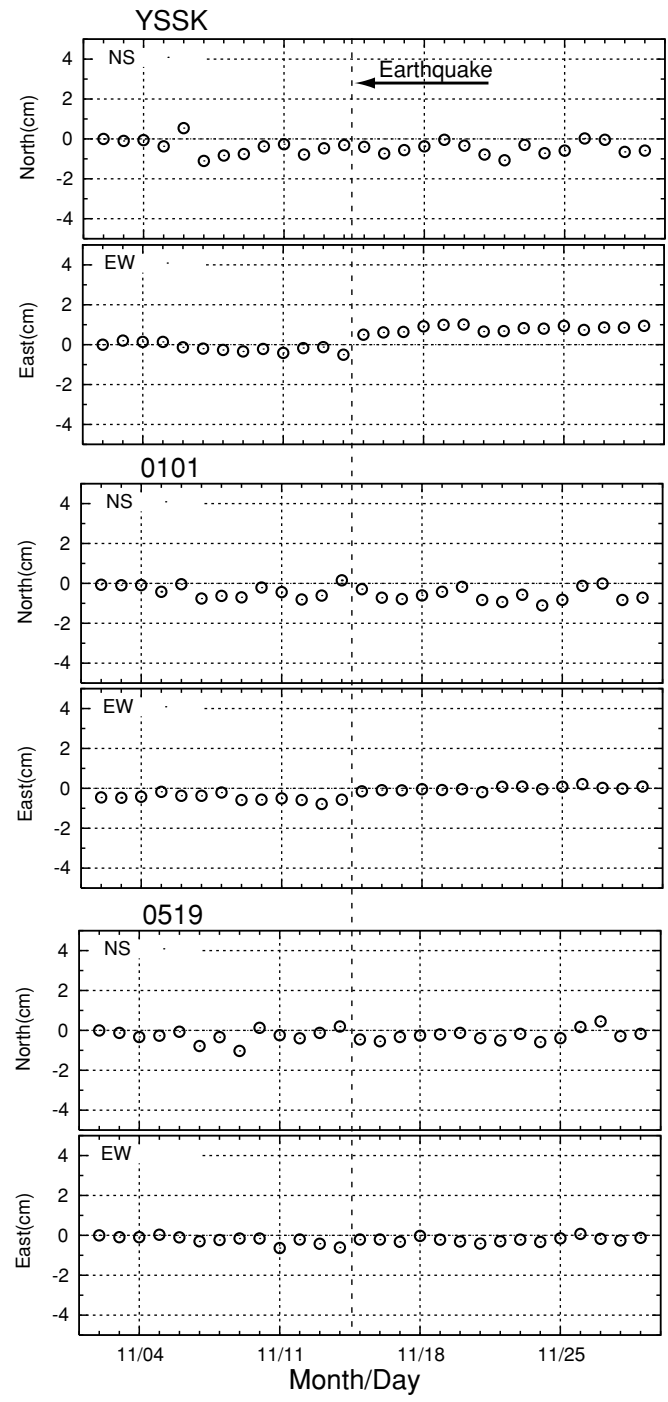

Fig. 2. Example of daily coordinates of several GPS sites.

(Fig. 1). The epicentral distances (900-1200 km) imply that the effect of the sphericity of the Earth in terms of theoretical crustal deformation computations is not large (Banerjee et al., 2005; Hashimoto et al., 2006). Therefore, we calculated the theoretical crustal deformation using the formula

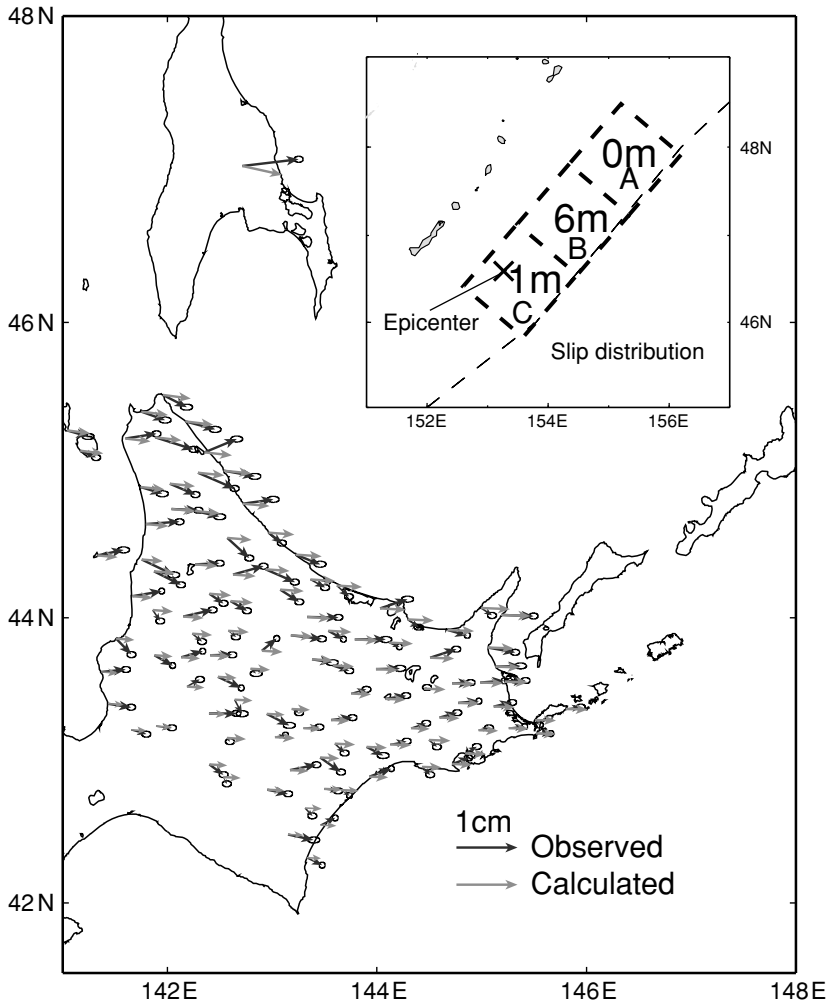

Fig. 3. Observed versus calculated horizontal displacement vectors at GPS sites with $2 \sigma$ errors. Inset shows the best-fit slip amounts on subfaults.

of Okada (1992) on elastic half-space medium. The size and top depth of the subfault are $100 \times 100 \mathrm{~m}$ and $5 \mathrm{~km}$, respectively. We first fixed the following fault parameters, strike $=214^{\circ}, \operatorname{dip}=15^{\circ}, \operatorname{slip}=92^{\circ}$, using the Global CMT solution. The mainshock epicenter is located at the northwestern edge of subfault-C. We searched for the best-fit slip combination of each subfault using a grid-search procedure for a slip in the range of $0-10 \mathrm{~m}$ at every $1-\mathrm{m}$ step. The misfit function is calculated as the quadratic sum of observed minus calculated vectors.

Figure 3 indicates the best-fit slip distribution and its displacement field at each site. We estimated a slip of $6 \mathrm{~m}$ in the central part, whereas small slips of $1 \mathrm{~m}$ and no slip 

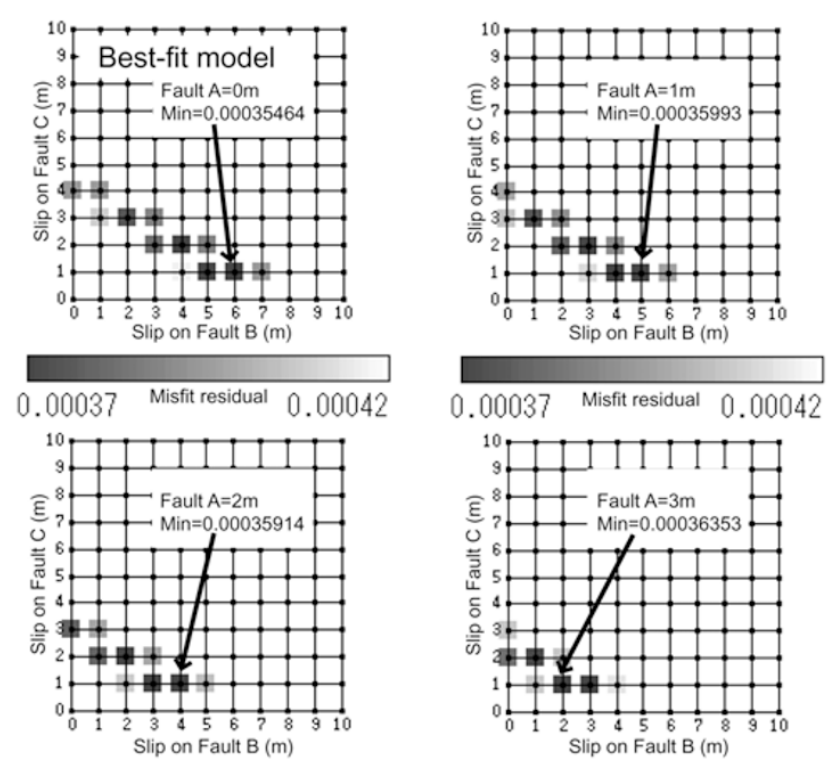

Fig. 4. Misfit residuals for each slip combination.

at all were estimated in the southern and northern parts of the focal region, respectively. The misfit residuals mapped in Fig. 4 also indicate the reliability of the relative large slip in the central part. The total seismic moment with rigidity $40 \mathrm{GPa}$ is $2.8 \times 10^{21} \mathrm{~N} \mathrm{~m}$, which is equivalent to $M_{\mathrm{w}}=8.2$. This value shows good agreement with that of the Global CMT solution $\left(M_{\mathrm{w}}=8.3\right)$.

\section{Discussion and Concluding Remarks}

The present result suggests a large slip in the central part but small slips in the southern and northern parts of the aftershock region. Y. Yamanaka (EIC seismological note, No. 183, 06/11/15 Kuril Islands; available at: http:// www.eri.u-tokyo.ac.jp/sanchu/Seismo_Note/2006/EIC183e .html) proposed a slip distribution model inferred from teleseismic body wave data. C. Ji (Rupture process of the 2006 NOV 15 Magnitude 8.3-KURIL Island Earthquake (Revised); available at: http://earthquake.usgs.gov/ eqcenter/eqinthenews/2006/usvcam/finite_fault.php) also estimated slip distribution from both the teleseismic body waves and the long period surface waves. These researchers concluded that there was a large slip in the central part of the aftershock region. However, Y. Yagi (Fault rupture imaging of the November 15 Kuril Islands earthquake (preliminary version); available at: http://www. geo.tsukuba.ac.jp/press_HP/yagi/EQ/Chishima/) suggests that teleseismic body wave data indicate a large slip in the southern part. The present geodetic study independently supports the results of the first two studies, which together strongly imply that the asperity of this earthquake was situated at the center of the aftershock region, and therefore, that its epicenter was situated at a location some distance from the main asperity. This proposal is also in agreement with the general suggestion that the epicenters of interplate earthquakes in northern Japan are located at the edge of the asperity (Yamanaka and Kikuchi, 2004).

Aftershock activity in the central part is low (Fig. 1). In other words, aftershocks occur around the asperity but not within it. This feature has been reported in many studies (e.g. Hartzell and Heaton, 1986; Yamanaka and Kikuchi, 2004). The fault geometry implies that the rupture propagated from southwest to northeast, that is, from a greater to a shallower depth. The stress drop in this segment with $2.5 \times M_{0} / S^{1.5}\left(M_{0}\right.$, seismic moment; $S$, dimension of fault $)$ is $4 \mathrm{MPa}$, which is a typical value for an interplate thrust earthquake (Bilek and Lay, 1999).

The slip distribution data also indicate that the rupture does not reach the Bussol Strait, where a NE-SW tensional boundary of the southwestern Kuril forearc sliver exists. A number of researchers have proposed that oblique subduction in the southwestern Kuril trench drives sliver translation to the southwest (Kimura, 1986; DeMets, 1992; Lobkovsky et al., 2006). However, the trench-perpendicular slip vector of this earthquake (Fig. 1), the direction of which is similar to that of the relative plate motion (Sella et al., 2002), indicates the absence of driven force in this region. These also may suggest that the Bussol Strait acts as a clear tectonic boundary of overlying plate controlled by interplate earthquake segmentation.

A $M_{\mathrm{s}}=8.0$ earthquake was recorded in 1915 in the area north of the 2006 focal region (Geller and Kanamori, 1977). However, there is no record of a tsunami associated with this event in Japan and Russia, even though there were residents near the source region. This suggests that the 1915 earthquake might not have been a typical interplate earthquake. The fact that there has been no recorded earthquakes after the 1915 event indicates that a 400-km-long seismic gap remains between the 2006 and the 1952 great Kamchatkan earthquakes. The size of this seismic gap suggests that there is a potential for an $M>8$ earthquake if the entire gap will be to rupture at once.

In this paper we demonstrate that continuous GPS data detect coseismic signals of a remote $M=8.3$ earthquake with a $1000-\mathrm{km}$ epicentral distance. This also suggests that the slip feature of the seismic fault can be estimated along a line from the central to southern Kuril Trench, where geodetic sites are sparse despite the frequent occurrence of great earthquakes.

Acknowledgments. We thank the Geographical Survey Institute of Japan and the International GNSS Service for the GPS data. Hypocenter data are from USGS PDE. We thank Manabu Hashimoto and Jeff Freymueller for valuable comments on the manuscript, and Dr. Nishida for proof reading. The figures were partially drawn by GMT software (Wessel and Smith, 1995).

\section{References}

Banerjee, F., F. Pollitz, and R. Burgmann, The size and duration of the Sumatra-Andaman earthquake from far-field static offsets, Science, $\mathbf{3 0 8}$, 1769-1772, 2005.

Beutler, G., M. Rothacher, S. Schaer, T. A. Springer, J. Kouba, and R. E. Neilan, The International GPS Service (IGS): An Interdisciplinary Service in Support of Earth Sciences, Adv. Space Res., 23, 631-635, 1999.

Bilek, S. and T. Lay, Rigidity variations with depth along interplate megathrust faults in subduction zone, Nature, 400, 443-446, 1999.

DeMets, C., Oblique convergence and deformation along the Kuril and Japan trenches, J. Geophys. Res., 97, 17615-17625, 1992.

DeMets, C., R. Gordon, F. Argus, and S. Stein, Effect of recent revisions to the geomagnetic reversal time scale on estimates of current plate motions, Geophys. Res. Lett., 21, 2191-2194, 1994.

Fedotov, S. A., Regularities of distribution of large earthquakes of Kam- 
chatka, Kuril Islands and North-Eastern Japan, Trans. Inst. Phys. Earth Zemli Akad. Nauk, 36, 68-93, 1965.

Geller, R. J. and H. Kanamori, Magnitude of great shallow earthquakes from 1904 to 1952, Bull Seism. Soc. Am., 67, 587-598, 1977.

Hartzell, S. H. and T. H. Heaton, Rupture history of the 1984 Morgan Hill, California, earthquake from the inversion of strong motion records, Bull. Seismol. Soc. Am., 76, 649-674, 1986.

Hashimoto, M., N. Choosakul, M. Hashizume, S. Takemoto, H. Takiguchi, Y. Fukuda, and K. Fujimori, Crustal deformation associated with the great Sumatra-Andaman earthquake deduced from continuous GPS observation, Earth Planets Space, 58, 127-139, 2006.

Hugentobler, U., S. Schaer, and P. Fridez, Bernese GPS Software Version 4.2, University of Bern, 515pp, 2001.

Kimura, G., Oblique subduction and collision: Forearc tectonics of the Kuril arc, Geology, 14, 404-407, 1986.

Lobkovsky, L. I., B. V. Baranov, R. G. Kulinich, and B. Y. Karp, The central Kuril Gap: Structure and seismic potential, Doklady Earth Sci., 409, 787-790, 2006.
Okada, Y., Internal deformation due to shear and tensile faults in a halfspace, Bull. Seismol. Soc. Am., 82, 1018-1040, 1992.

Sella, G. F., T. H. Dixon, and A. Mao, REVEL: A model for recent plate velocities from space geodesy, J. Geophys. Res., 107, doi:10. 1029/2000JB000033, 2002.

Song, T. A. and M. Simons, Large trench-parallel gravity variations predict seismogenic behavior in subduction zone, Science, 301, 630-633, 2003.

Yamanaka, Y. and M. Kikuchi, Asperity map along the subduction zone in northeastern Japan inferred from regional seismic data, J. Geophys. Res., 109, B07307, doi:10.1029/2003JB002683, 2004.

Wessel, P. and W. H. F. Smith, New version of the generic mapping tools released, Eos Trans. AGU, 76, 329-336, 1995.

H. Takahashi (e-mail: hiroaki@mail.sci.hokudai.ac.jp) and M. Kasahara 